\title{
Correction: Romancing science for global solutions: on narratives and interpretative schemas of science diplomacy
}

\author{
Charlotte Rungius (1) \& Tim Flink (D)
}

Correction to: Humanities and Social Sciences Communications https://doi.org/10.1057/s41599-020-00585-w, published online 23 September 2020.

The original abstract contained some erroneous text introducing in the typesetting process:

In recent years, the concept of science diplomacy has gained remarkable ground in public policy. Calling for closer cooperation between actors from science and foreign policy, it is ocediplomacy.org/editorial/2017/optimism-pessimism-and-science-diplomacyften being promulgated as a hitherto neglected catalyst for international understanding and global change. On what grounds science diplomacy entertains these high hopes, however, has remained unclear, and-as a blind spot-unaddressed in a discourse mostly shaped by policy practitioners. Recognizing that the discourse on science diplomacy is still unspecific about how its means and ends should fit together and be comprehended, we reconstruct the concept and its discourse as a materialization of actors' interpretative schemas and shared assumptions about the social world they constantly need to make sense of. Science diplomacy is presented as a panacea against looming threats and grand challenges in a world facing deterioration. The prerequisite for such a solutionistic narrative is a simplified portrait of diplomacy in need of help from science that-romanticized in this discourse-bears but positive properties and exerts rationalizing, collaborative and even pacifying effects on a generic international community in its collective efforts to tackle global challenges. We conclude that these interpretative schemas that idealize and mythify science as overall collaborative, rationalizing and complexity-reducing are problematic. First, because the discourse misconceives ideals and norms for real and will therefore disappoint social expectations, and second, because science is likely to be instrumentalised for political purposes.

The abstract has been corrected to read:

In recent years, the concept of science diplomacy has gained remarkable ground in public policy. Calling for closer cooperation between actors from science and foreign policy, it is often being promulgated as a hitherto neglected catalyst for international understanding and global change. On what grounds science diplomacy entertains these high hopes, however, has remained unclear, and-as a blind spot-unaddressed in a discourse mostly shaped by policy practitioners. Recognizing that the discourse on science diplomacy is still unspecific about how its means and ends should fit together and be comprehended, we reconstruct the concept and its discourse as a materialization of actors' interpretative schemas and shared assumptions about the social world they constantly need to make sense of. Science diplomacy is presented as a panacea against looming threats and grand challenges in a world facing deterioration. The prerequisite for such a solutionistic narrative is a simplified portrait of diplomacy in need of help from science that — romanticized in this discourse-bears but positive properties and exerts rationalizing, collaborative and even pacifying effects on a generic international community in its collective efforts to tackle global challenges. We conclude that these interpretative schemas that idealize and mythify science as overall collaborative, rationalizing and complexity-reducing are problematic. First, because the discourse misconceives ideals and norms for real and will therefore disappoint social expectations, and second, because science is likely to be instrumentalised for political purposes. 
(c) Open Access This article is licensed under a Creative Commons Attribution 4.0 International License, which permits use, sharing, adaptation, distribution and reproduction in any medium or format, as long as you give appropriate credit to the original author(s) and the source, provide a link to the Creative Commons license, and indicate if changes were made. The images or other third party material in this article are included in the article's Creative Commons license, unless indicated otherwise in a credit line to the material. If material is not included in the article's Creative Commons license and your intended use is not permitted by statutory regulation or exceeds the permitted use, you will need to obtain permission directly from the copyright holder. To view a copy of this license, visit http://creativecommons.org/licenses/by/4.0/.

(C) The Author(s) 2020 